steps of the process of change to the new order of things follow in rapid succession. An event may be long in preparation, but its consummation takes place with a rapidity which must be experienced to be fully appreciated.

Another question of the greatest and at present time-absorbing interest is, what can be done to force the schools to properly prepare students for the colleges and universities? We use the word 'force,' rather than 'induce,' because all arguments except those which can be supported by the pressure of the entrance examinations fail to awaken these schools to the needs of science-teachers in these higher institutions. The following remarks appeared in Science of May 18, 1883, and can be used appropriately in this connection :-

"In the brief, informal discussions [which took place at the Springfield meeting], the opinion was very generally expressed, that one of the most important questions with which we have to deal, and one which needs immediate attention, is the preparation necessary for the study of natural science in colleges. The great difficulty in making a success of college instruction in the sciences lies in the fact that not one young man in twenty knows either how to observe, or how to think about facts of observation. His education in that line is very deficient, or else entirely wanting; he is utterly helpless without his books, and seems quite unable to see or to correlate facts for himself. No other branch of the curriculum is so inefficiently treated by the preparatory schools and academies. It is the reverse of right that the college professor, with a class of from forty to eighty men, should have to make the vain attempt to teach the lowest step in the observational sciences. Methods which can alone guarantee success in imparting to the eye and the mind the rudiments of science cannot be employed under such conditions. Moreover, it is a matter for the deepest regret, that young men who are soon to be in places in the world where they have no books, and where the keenest exercise of the powers of observation, and the judgment of facts, are demanded, should in so many cases have no opportunity, or next to none, either in school or college, for the acquisition of a training upon which the success of their lifework, in the larger number of professions and occupations, is dependent.

"It is to be hoped that one needs only to mention such objects as these, to bespeak for this new association the sympathy and support of all naturalists, and earnest workers in science."

In the above remarks expression is given to opinions some of which, we know, will meet with general approbation, and others will very properly be regarded as merely personal views. We shall, however, have attained the object for which this address was written, if we have made it evident that this society can, if it be so disposed, take up questions of the highest importance to the public service of science, and help towards their solution by its deliberations. We believe it can do this wherever it can unite the majority of scientific men in opinion and in effort. The power which can be wielded by such an organization is in exact proportion, not to its numbers, but to its earnestness, determination, and especially its fearless support of what is just and right.

After referring further to the work of the society, as outlined in the article already referred to, Professor Hyatt proceeded:--

Enough papers to occupy nearly the whole time which can be devoted to them will be announced by the secretary. Though these and kindred subjects will be our most important objects, it was due to the society to show that its scope was not necessarily wholly confined to such details; and this we have endeavored to accomplish in the first part of the preceding remarks.

In conclusion, we beg leave to report that the executive committee has had great responsibilities thrust upon it since the first meeting. These they have endeavored to meet to the best of their ability; and we believe that the present attendance, and the many honorable names on our list, will help to extenuate the errors inseparable from haste and overwork.

In place of Professor Clarke, whose absence in Europe we regret, the executive committee appointed Dr. C. S. Minot, and he has faithfully and acceptably performed the duty of secretary pro tem.

\section{THE NEW MORPHOLOGICAL ELEMENT OF THE BLOOD.}

WITHIN recent years it has been established beyond doubt by the labors of Hayem, Bizzozero, and others, that there exists in the blood of mammals, and apparently of other vertebrates, a third type of corpuscle, differing morphologically from both the red and the white corpuscle, and possessing certain distinctive properties of the greatest importance in coagulation. These elements were called hematoblasts by Hayem upon the supposition that they are eventually transformed into red corpuscles. As this view is by no means established, it will be better to speak of them as blood-plates, the name given to them by Bizzozero. These blood-plates must not be confounded with the 'invisible corpuscles' of Norris. The latter, according to the testimony of most observers, are simply ordinary red corpuscles, from which the haemoglobin has been removed by the method of preparation. As might be supposed, the presence of these bodies was more or less clearly noticed by some of the many observers who for years past have made the blood a subject of investigation. That they escaped detection in the great majority of cases, is owing, doubtless, to the very rapid alterations which they undergo after the blood is shed, unless especial measures are taken to preserve them.

To Hayem belongs the credit of their real discovery. His investigation of their form, and, to a certain extent, of their properties, was so thorough, and his method of demonstrating their presence so simple, that the attention of other observers was forced to the subject; and his results were soon confirmed, with the exception of certain details of structure which are still open to investigation. On account of the quickness with which they are destroyed after the blood has escaped from the vessels, it is necessary to make use of certain preservative liquids which have the power of fixing these corpuscles in their normal shape. The solution recommended by Hayem is composed, of water 200 parts, sodium chloride 1 part, sodium sulphate 5 parts, and mercuric chloride .50 parts. Bizzozero recommends a $.75 \%$ solution of sodium chloride, to which some methyl aniline violet has been added. Osmic-acid solution, $1 \%$, may also be used. To obtain good specimens of the blood- 
plates, the following method is suggested by Laker. A drop of preservative liquid is placed on the slide, and a drop of blood on the cover-slip, and the slip laid quickly on the slide, so that the two drops come in contact. As many as possible of the red corpuscles are then drained off by means of a piece of filterpaper applied to the slip on the side opposite to the drop of preservative liquid; or the two drops may be placed on the slide, and the cover-slip laid on from the side of the preservative liquid. The one precaution which it is necessary to observe is to lose as little time as possible in transferring the blood to the preservative liquid.

Obtained in this way, the blood-plates of the mammal are small, non-nucleated, discoid bodies from one-fourth to one-half the size of the red corpuscles. Hayem states that they are bi-concave, like the red corpuscles, and that many of them have a slight greenish or yellowish color due to the presence of haemoglobin. Bizzozero, on the other hand, maintains that they are perfectly colorless and not bi-concave. Mayet supports Hayem's statement with regard to the presence of haemoglobin in some, at least, of the blood-plates; while Laker thinks that the pale greenish hue possessed by them is owing to a reflection of light from the upper surface. The same tint may be observed in white corpuscles; and, furthermore, when the blood-plates are collected in masses, this color does not become more distinct. Laker confirms Hayem's statement that the plates are bi-concave, and says that he has often obtained from them the well-known optical phenomenon shown by the red corpuscles. The blood-plates occur in considerable numbers. According to Hayem, they are forty times more numerous than the white corpuscles, and twenty times less numerous than the red corpuscles. Staining-reagents have but little action upon them. Water causes most of them to disappear, though some individual plates may resist its action for a long time. Dilute solutions of acetic acid or caustic alkali quickly destroy them, while a $35 \%$ solution of caustic potash is without any marked action. Laker states, that, in their general behavior towards reagents, they resemble most the nucleus of the white corpuscle. With regard to their origin, nothing is known. That they are not simply remnants of broken down white corpuscles is evident, in the first place, from the typical form they possess, and, in the second place, from the difference in chemical composition between the two, as shown by reagents. Bizzozero has proved conclusively that they are not pathological formations arising after the blood has been shed, since he has seen and studied them in the mesenteric bloodvessels of living animals.

Hayem believes that the blood-plates are finally transformed into red corpuscles. His reasons for this belief are as follows: 1. They possess a similar form; 2. They have a similar chemical composition, both containing haemoglobin; 3. The appearance of many intermediate forms between the typical bloodolate and the ordinary red corpuscle, especially in certain pathological conditions - after a severe hemorrhage, for instance. Under these conditions, Hay- em states that the plates become more abundant, and gradually return to their normal proportion as the number of red corpuscles increases. In the main, these statements are confirmed by Mayet; but, as we have said, the similarity in form, and the presence of haemoglobin, are denied by others, especially Bizzozero; and neither Bizzozero nor Laker was able to detect any intermediate forms between the bloodplates and the red corpuscles. Perhaps the most interesting result that has come out of the study of these elements is the knowledge of the important part they take in the coagulation of blood. This property has been thoroughly investigated by Bizzozero. His conclusions may be briefly stated as follows. Liquids which have a tendency to prevent coagulation also preserve the blood-plates more or less completely from destruction. Experiments made upon blood kept within the living blood-vessel show that as long as the blood remains uncoagulated the blood-plates are unchanged, while the rapid coagulation of portions of the blood removed from the vessel is always preceded by a destruction of the plates and the formation from them of granular masses. When a drop of blood is whipped with small threads for about fifty seconds, the threads withdrawn, washed gently in .75\% sodium-chloride solution, and then examined under a microscope in the methylated soda solution, they are seen to be covered with a layer of plates, together with some white corpuscles. If the whipping is continued longer, the plates are converted into a granular mass, and covered with a layer of fibrine. If this process is reversed, and a slow stream of blood is allowed to pass over a thread watched under the microscope, the different stages of the process can be observed, - the deposition of the plates, their fusion into a granular mass, and the subsequent formation of fibrine. When one of these threads, to which the blood-plates and a few red and white corpuscles are adhering, is added to a liquid containing the two fibrine factors, but not fibrine ferment, coagulation takes place. That this coagulation is not owing to the thread or to the red corpuscles is easily demonstrated: it must result from the addition of either the white corpuscles or the bloodplates. When, however, bits of tissues rich in leucocytes - such as the spleen, lymph-glands, medulla of bone - are added to the above liquid, no coagulation at all, or else a very imperfect coagulation, follows. The inference, then, is, that the coagulation in the first case results from the addition of the blood-plates. In his latest communication, Bizzozero states, that if to a few drops of peptonized plasma, which coagulates very slowly, some water or carbon dioxide is added, and the preparation is examined under the microscope, the blood-plates will be seen collected into large heaps in which the individual blood-plates may still be recognized. In a few minutes the plates fuse together into a granular mass which becomes vacuolated, and at this moment coagulation begins. From the periphery of the granular heaps hundreds and thousands of fine processes radiate, and form a network which slowly spreads into the surrounding plasma. 
Bizzozero attributes the origin of thrombi in bloodvessels to the destruction of these corpuscles. $\mathrm{He}$ has been able to watch the process of formation in the mesenteric vessels of living animals when a lesion of the walls of the vessels was produced in any way.

In the blood of animals with nucleated red corpuscles, Hayem has described a form of corpuscle which has properties analogous to those possessed by the blood-plates of mammals. These corpuscles may be preserved for study by the use of the liquids mentioned above. They are colorless, nucleated, slightly flattened bodies, bearing a general resemblance in shape to the red corpuscles, though usually more elongated at one or both of the poles. They vary greatly in size, but as a rule are somewhat larger than the white corpuscles. They are distinguished from the white corpuscles mainly by a difference in form and by the changes which they undergo after the blood has been shed. The white corpuscles are always more or less spherical, while the plates are flattened disks. After the blood has been shed, they become exceedingly viscous, and form granular masses from which fibrous processes radiate. Their functional value in coagulation appears to be the same as that of the blood-plates in mammals with non-nucleated red corpuscles.

Wilitam H. Howelr.

\section{THE COMSTOCK LODE.}

Geology of the Comstock lode and the Washoe district. By George F. Becker. (Monographs U.S. geol. surv., iii., with an atlas.) Washington, $1882.422 \mathrm{p} .44^{\circ}$.

THe appearance of the second of the new series of monographs published by the U.S. geological survey will be greeted with pleasure by the scientific world, not only on account of the amount of new information it contains regarding the geological and physical character of one of the most important ore-deposits on the globe, but also as an index of the increasing interest which is being taken in this country in a very important but comparatively new branch of geological research. Becker's report contains, with perhaps one exception, the most considerable contribution yet made by an American to microscopical petrography, and deserves for this reason, aside from its other merits, high commendation.

Referring, for a historical, economic, and technical treatment of the Comstock lode, to the works now in preparation by Messrs. Lord and Eckart, the author devotes himself to a purely scientific investigation of this interesting region. A résumé of the results reached by von Richthofen, Zirkel, King, and Church, is given, which is followed by a detailed description of the rocks in connection with which the ore-deposits occur. This work is carefully done, and, notwithstanding a very apparent lack of acquaintance with the literature and many important methods of modern petrography, is a valuable contribution to the subject. For instance : the actual presence of the suspected sodalite in the granite might easily have been placed beyond a doubt by a simple microchemical test. Again : the measurement of extinction-angles would have been much more satisfactory had they been made on cleavage pieces from their isolated powder instead of in the sections; while Boricky's test would certainly have yielded as good results as Szabo's.

The variety of rocks in the area studied is very great, comprising, in order of their ages, granite, metamorphics, granular diorite, porphyritic diorite, metamorphic diorite, quartzporphyry, earlier diabase, later diabase, earlier hornblende andesite, augite andesite, later hornblende andesite, and basalt. None of these exhibit in their occurrence or structure any thing very striking or abnormal, if we except the sodalite in the granite, whose presence is, however, left very doubtful. Of especial interest are the decomposition processes, which have altered the rocks in the area between the Comstock and Occidental lodes almost past recognition. These are thought to be due to solfataric action, which was not earlier than the eruption of the later hornblende andesite; and they have received a good share of the author's attention. All the rocks of this area are equally decomposed; and, in the case of all, the same minerals have undergone the same alteration. Hornblende, augite, and mica change into chlorite, and this in turn generally to epidote, though sometimes to a mixture of quartz, calcite, and limonite. The felspar becomes filled with secondary fluid inclusions, and finally forms a mass of calcite, quartz, and a substance of unknown character, which, according to the author, is certainly not kaoline.

By far the most interesting results of the author's studies, from a petrographical standpoint, are those arrived at in reference to the origin and nature of that much-discussed rocktype, propylite. As is well known, this name was given by von Richthofen to certain early tertiary, andesitic rocks of Hungary, possessing a fibrous green hornblendic constituent and a granitic habit. Both von Richthofen and Zirkel regarded the Washoe district as a locality where this type was especially well developed; and the present author entered upon his work fully convinced of the correctness of their views. All the more interesting, then, is the fact that a careful and elaborate study of these 